\title{
RECITAL DE POESIA: TEXTO, VOZ E CORPO
}

\author{
POETRY RECITAL: TEXT, VOICE AND BODY
}

DOI: 10.23926/RPD.2526-2149.2020.v5.n2.p801-822.id747

\author{
Rozane Fermino \\ Professora na Instituição \\ $\mathrm{SED} / \mathrm{SC}$ \\ Graduada em Letras - \\ Português e Inglês (FACEL) \\ profrozanefermino@gmail.c \\ om
}

\section{Camila Grimes}

Professora na Instituição SED/SC

Doutoranda em Educação (FURB)

cgrimes@furb.com

\section{Flávio Booz}

Professor na Instituição SED/SC

Graduado em Pedagogia

(FACINTER)

flaviobooz@gmail.com

\section{Suzana Abromovicz}

Professora na Instituição SED/SC

Graduada em Letras -

Português e Espanhol

(UNITINS)

abromoviczsuzy@gmail.com
Resumo: A presente pesquisa refere-se ao Projeto Recital de Poesia, desenvolvido desde 2016 na Escola de Educação Básica Manoel Vicente Gomes, escola pública estadual, situada no munícipio de Major Gercino em Santa Catarina, envolvendo os estudantes do Ensino Fundamental Anos Finais e do Ensino Médio. A investigação possui como objetivo geral aprimorar as habilidades linguísticas em sua plenitude, contemplando as diversas formas do uso da linguagem, através da escrita, da oralidade e da expressão corporal. $\mathrm{O}$ presente artigo seguiu o modelo de pesquisa com abordagem qualitativa, sendo que os dados foram obtidos através da análise dos diários reflexivos referentes ao ano de 2019 dos estudantes, bem como do relato de prática da professora orientadora. Dentre os resultados obtidos, destaca-se a importância que este projeto assumiu na vida dos discentes e a sua função social de envolver a família na escola, ainda a autonomia conquistada através da escrita e do reconhecimento de sua expressão pessoal.

Palavras-chave: Recital de Poesia. Linguagens. Escola Pública. Interação Social.

\begin{abstract}
This research refers to the Poetry Recital Project, developed since 2016 at the Manoel Vicente Gomes Basic Education School, a public state school, located in the municipality of Major Gercino in Santa Catarina, involving elementary and high school students. The general objective of the investigation is to improve linguistic skills, including the various forms of language use, through writing, orally and body expression. This article followed the research model with a qualitative approach, and the data were obtained through the analysis of the students reflective diaries for the year 2019, as well as the practice report of the guiding professor. Among the results obtained, we highlight the importance that this project has assumed in the students lives and its social function of involving the family, in school, even the autonomy achieved through writing and the recognition of their personal expression.
\end{abstract}

Keywords: Poetry recital. Languages. Public school. Social interaction. 


\section{INTRODUÇÃO}

"Um dia estava no castelo, No outro no gramado,

É uma princesa guerreira Que vai deixar seu legado. Jamais desistiu

Mostrou que tem poder A princesa do castelo Também pode ser você."

(Estudante 06, O sonho de uma princesa, 2019)

O Projeto Recital de Poesia - texto, voz e corpo, iniciou em 2016 na Escola de Educação Básica Manoel Vicente Gomes, envolvendo os estudantes do Ensino Fundamental Anos Finais e do Ensino Médio, sendo um projeto contínuo de Língua Portuguesa orientado pela docente deste componente curricular.

Nos contextos escolares não é comum o desenvolvimento de projetos relacionados com a educação estética no sentido de promover a formação humana integral perpassando pelas competências da linguagem oral e escrita.

Nesse sentido, a educação estética é essencial na escola, pois visa uma educação que promove o desenvolvimento do sentimento, da expressão e da criação humana. $\mathrm{O}$ desenvolvimento da poesia na escola, na perspectiva da educação estética, permite a formação humana integral, com sujeitos capazes de compreender a conexão entre a razão e a emoção, a totalidade da completude humana (FIAMONCINI; 2006). Nesse sentido, Lacerda e Gonçalves (2009, p.112), acrescentam que: "a estética permite ao ser humano ler o mundo através de um olhar que concilia a racionalidade com a emocionalidade".

O desenvolvimento deste projeto justifica-se pela notória falta de vivências poéticas no processo de ensino e aprendizagem dos estudantes, bem como de todos os benefícios para a construção das habilidades semióticas que estas vivências trazem consigo. A semiose contida nas linguagens está integrada neste projeto no que tange à utilização dos signos verbais e nãoverbais, que propiciam a sociointeração e as representações de mundo do estudante (SANTA CATARINA, 2014).

O projeto "Recital de Poesia" possui como objetivo geral aprimorar as habilidades linguísticas em sua plenitude, contemplando as diversas formas do uso da linguagem, através da escrita, da oralidade e da expressão corporal, tendo como objetivos específicos: a) motivar os estudantes a lerem poemas; b) conhecer novos autores; c) conhecer a estrutura de um poema; d) construir uma produção textual do gênero poema; e) utilizar a conotação e as figuras de linguagem; f) interpretar poemas; g) expressar-se através de sua produção; e h) reconhecer sua 
identidade no poema escrito; i) manifestar-se esteticamente por meio da dramatização do texto e demais elementos cênicos.

O texto está organizado nas seguintes seções: aportes teóricos da pesquisa, pressupostos metodológicos adotados, resultados e discussões que apresentam as vozes dos sujeitos em relação ao projeto Recital de Poesia, bem como seu desenvolvimento na comunidade escolar e as considerações finais do estudo.

A seguir, apresentamos os aportes teóricos desta pesquisa.

\section{REFERENCIAL TEÓRICO}

“O arco-íris é assim Cheio de diferença Uma cor é tristonha Outra entusiasmada E você?

Tem alguma cor aprisionada?"

(Estudante 41, Arco- íris: as cores da diversidade, 2019)

Desenvolver um projeto que contemple todas as habilidades das Linguagens é essencial para promover a inserção do estudante no universo da Língua Portuguesa em sua totalidade, esta importância é abordada na Base Nacional Comum Curricular - BNCC (2017), que considera como eixos que correspondem às práticas de linguagem a oralidade, a leitura/escuta, a produção (escrita e multissemiótica) e a análise linguística/semiótica. Desta forma, o Projeto Recital de Poesia versa sobre estes conceitos com o intuito de promover uma formação humana integral.

A poesia está intrinsecamente ligada a Língua Portuguesa, muitas vezes, poema e poesia são confundidos e utilizados como sinônimos, porém:

Melhor seria dizer que a poesia ora é a própria denominação do gênero lírico, ora
significa a produção de um poeta. Ao passo que o poema é uma composição textual
em versos. No entanto, nem todos os textos construídos dessa forma, isto é, linha
abaixo de linha formando estrofes, contêm poesia. E vice-versa, pois vamos encontra-
la até em outras formas de arte que não a literária (SORRENTI, 2007, p. 58).

Neste sentido, a escrita de um poema deve primar por ser também arte a quem lê, a quem ouve, a quem interpreta ou dramatiza. Por todas estas riquezas que o gênero poema traz consigo é que a escola oferece um espaço propício para esta construção, independente da faixa etária dos estudantes, Carlos Drummond de Andrade faz um apelo "O que eu pediria à escola, (...) era considerar a poesia como primeira visão das coisas e mesmo veículo de informação teórica e prática, preservando em cada um o fundo mágico, lúdico, intuitivo e criativo que se identifica com a sensibilidade poética" (ANDRADE, 1974, p. 05). 
A poesia é impregnada de arte, o poema é arte. A arte presente nas Linguagens é expressa através da escrita, da fala e do corpo, "a arte serve para dar sentido à existência, (...) A poesia em especial, por mobilizar o lado intuitivo e emocional do homem, sempre relegado a segundo plano nessa cultura racionalista, torna-se hoje, artigo de primeira necessidade." (SILVA, 2009, p. 105).

Sorrenti (2009) diz que a tarefa de apresentar a poesia para os estudantes ficou delegada a escola, porém esta pode não obter êxito e criar o desgosto pelo gênero, conforme for abordada, pois este gênero demanda tempo e paciência para ser desenvolvido. Ainda, salienta que não basta apresentar um texto de qualidade para o estudante, é preciso promover a aproximação através da motivação e do entusiasmo de um professor que seja mediador na construção de um estudante protagonista de seu aprendizado.

Neste sentido, sobre o papel do professor mediador, Freire (1996, p.78) diz que "Ninguém pode conhecer por mim assim como não posso conhecer pelo aluno. O que posso e o que devo fazer é, na perspectiva progressista em que me acho, ao ensinar-lhe certo conteúdo, desafiá-lo a que se vá percebendo na e pela própria prática, sujeito capaz de saber”.

Ainda nesta perspectiva, o professor deve instigar o estudante a descobrir onde pode chegar e assumir sua identidade:

\begin{abstract}
Como os demais saberes, este demanda do educador um exercício permanente. É a convivência amorosa com seus alunos e na postura curiosa e aberta que assume e, ao mesmo tempo, provoca-os a se assumirem enquanto sujeitos sócios-históricosculturais do ato de conhecer, é que ele pode falar do respeito à dignidade e autonomia do educando (FREIRE, 1006, p. 04)
\end{abstract}

$\mathrm{O}$ trabalho com o gênero poema, com o intuito de promover autonomia e aprendizagem significativa, produz efeitos no desenvolvimento da Língua Portuguesa no que tange, segundo Novais (2012), ao desenvolvimento da consciência fonológica, a partir dos exercícios que envolvem os jogos sonoros da linguagem como o uso das rimas, elementos próprios dos poemas. Ainda, auxilia na ampliação das habilidades de leitura, ao abordar as figuras de linguagem, com as quais a poesia se serve, contribuindo para a formação voluntária do leitor com autonomia, capaz de ir a novos lugares através do uso e da interpretação destas. E por fim, traz que o estudo da poesia, no que diz respeito ao letramento literário, atua no desenvolvimento de valores estéticos, pois trabalha a questão da formação do gosto artístico.

No que diz respeito a aprendizagem da escrita e da leitura, Ribeiro (2007) considera fundamental a mobilização dos estudantes em situações que promovam o diálogo, o trabalho em equipe, e embate de opiniões, bem como "a fomentação da curiosidade de aprender; a 
descoberta e desenvolvimento, nas dimensões cultural, lúdica e estética da Língua, do gosto de falar, de ler e de escrever." (RIBEIRO, 2007, p. 73)

O poema versa sobre os mais variados conflitos, estados de espíritos e sentimentos. Além desta amplitude de temas, o trabalho com a produção de texto do gênero poema na educação básica, oferta práticas literárias com "textos que permitam uma convivência mais sensível com o outro, consigo mesmo, com os fatos do cotidiano, com a vida e com a linguagem.” (PINHEIRO, 2018, p. 123)

A construção de um conhecimento prazeroso ao estudante para que então ocorra uma produção textual do gênero poema exitosa, é fundamental para que se desenvolvam as habilidades correspondentes a Língua Portuguesa, pois "O prazer se apresenta intimamente associado às crenças e ao grau de conhecimento que possuímos a respeito do objeto ou situação colocados à disposição dos nossos sentidos" (NOVAIS, 2012, p. 38).

Transformar os estudantes em poetas é uma forma de que eles próprios se reconheçam como "porta-voz da coletividade" (SILVA,2009, p.105), capazes de colocar através de palavras o que sentem e não seriam capazes de expressar de outra forma. Na relação entre poesia e escola, Sorrenti (2009) reflete que "Como uma violeta em botão escondida no meio das folhas, vamos deixa-la desabrochar. Nunca é tarde para inventar um vasinho de poesia-violeta no coração do aluno - de qualquer idade - cuja beleza e sensibilidade o alimentarão por toda a vida."

A seguir descrevemos os pressupostos metodológicos que nortearam a investigação.

\section{NO MEIO DO CAMINHO HAVIA POESIA}

"O melhor de viajar assim É que não tem turbulência no avião Não há viagem mais segura Que viajar no mundo na imaginação!"

(Estudante 17, Vamos viajar, 2019)

O presente artigo seguiu o modelo de pesquisa com abordagem qualitativo que analisa indutivamente os dados levantados. De acordo com Godoy (1995), a pesquisa qualitativa tem como principal preocupação o estudo e a análise do mundo empírico em seu ambiente natural, valorizando o contato direto e delongado do pesquisador com o ambiente e a situação.

A palavra escrita ocupa lugar de destaque nessa abordagem, desempenhando um papel fundamental tanto no processo de obtenção dos dados quanto na disseminação dos resultados. Além disso, os pesquisadores qualitativos buscam compreender o que estudam considerando todos os pontos de vista dos participantes como essenciais: 
Visando à compreensão ampla do fenômeno que está sendo estudado, considera que todos os dados da realidade são importantes e devem ser examinados. O ambiente e as pessoas nele inseridas devem ser olhados holisticamente: não são reduzidos a variáveis, mas observados como um todo (GODOY, 1995, p. 62).

Os dados foram coletados por meio dos diários reflexivos dos estudantes, "os diários são um instrumento para promover uma reflexão pessoal do aluno sobre seu processo de aprendizagem" (MICCOLI, 2007, p. 47). Ou seja, o diário reflexivo é uma forma de acompanhar o processo de construção de pensamentos dos estudantes, bem como de sua avaliação e autoavaliação.

O diário reflexivo foi escolhido como instrumento de pesquisa pois, conforme Liberali (1999), permite uma reflexão crítica por meio do gênero discursivo que é utilizado no mesmo, "acreditamos que esse megainstrumento possa criar as condições e ser o palco para o desenvolvimento de um tipo de reflexão que, além de capturar a prática, crie a base para a crítica consciente dessa ação, sua colocação sócio-histórica, e transformação" (LIBERALI, 1999, p. 32). A escrita original dos sujeitos, foi mantida nos excertos e os procedimentos éticos necessários foram adotados no que diz respeito ao anonimato dos sujeitos, estes sendo voluntários na escrita de seus diários reflexivos, considerando a proteção da integridade e dos direitos dos participantes.

Os estudantes do Ensino Fundamental Anos Finais e do Ensino Médio, foram convidados no ano de 2019, a participarem de forma voluntária na escrita dos diários reflexivos com suas impressões sobre o projeto Recital de Poesia.

Os trechos dos poemas citados nas epígrafes, foram extraídos das produções autorais dos estudantes, referente aos anos de 2018 e 2019, sendo que estes também foram apresentados no evento Recital.

O projeto denominado "Recital de Poesia", desenvolvido na disciplina de Língua Portuguesa, iniciou em 2016 na Escola de Educação Básica Manoel Vicente Gomes, uma escola pública da rede estadual de Santa Catarina, localizada no munícipio de Major Gercino, atendendo 156 estudantes do Ensino Fundamental - Anos Finais e do Ensino Médio, sendo que todos são contemplados pelo projeto que continua em vigência.

A análise dos dados gerados considera as regularidades das falas dos sujeitos envolvidos no projeto em relação às temáticas de pesquisa. Além disso, a descrição das ações do projeto foram essências para a construção das discussões.

Na sequência, analisaremos o desenvolvimento do Projeto e seus resultados. 


\section{Resultados}

"Se não eu,

Quem por mim irá lutar?

Não fomos feitas para a guerra

Mas temos garra para tentar."

(Estudante 89, O poder das mulheres, 2018)

O projeto "Recital de Poesia", traz para a escola um gênero com potencial em explorar a amplitude das linguagens e desenvolver estas no estudante, ainda busca despertar o gosto pela leitura poética considerando que:

A poesia é um gênero mais difícil e pouco cultivado entre os leitores brasileiros. O fato pode ser percebido no mercado editorial. Percorrendo as páginas de um catalogo de editora, o número de títulos de poesia é mínimo, comparado àqueles de narrativa em prosa. Os editores alegam que publicam pouco porque "poesia não vende" (SORRENTI, 2009, p.19).

O desenvolvimento das habilidades que tangem às linguagens, através do projeto, trata de imergir na poesia, formando estudantes leitores e produtores de poemas, "oferecendo-lhes a possibilidade de combinar sons e imagens, satisfazendo seu gosto pela criatividade, pela experimentação linguística e pela reelaboração do real” (SORRENTI, 2009, p. 15).

No que reflete a preocupação do Projeto Recital de Poesia com o desenvolvimento das habilidades do estudante na área das Linguagens, o Estudante 42 afirma que:

“Acerca do recital de poesia minhas opiniões são positivas, pois há um estudo acerca da poesia para depois fazer a poesia. O recital de poesia é extremamente benéfico pois envolve a escrita, declamação, teatro e desenho. É uma compilação de várias partes da Arte" (Diário Reflexivo, estudante 42, 2019/II).

De acordo com a professora orientadora do projeto, uma das autoras desta pesquisa, que considera a unidade escolar como uma família, o projeto é de grande complexidade e importância para a comunidade escolar, bem como para a docente:

\footnotetext{
“Aplicar este projeto na \#FamíliaManoel é a realização de um sonho como professora de Língua Portuguesa. É de suma importância trabalhar de maneira dinâmica, mas sem deixar de ensinar o que precisa e deve ser aprendido. Vejo que dessa forma os estudantes internalizam conhecimento, mostram aprendizagem e desenvolvem habilidades que até então não sabiam que tinham" (Diário Reflexivo, docente, 2019/II).
}

Para o primeiro contato com o gênero textual, a professora leva para a sala de aula alguns poemas de famosos escritores brasileiros, como Olavo Bilac, Braúlio Bessa, Gonçalves Dias, Cecília Meireles, Mário Quintana, entre outros, e também poemas produzidos por estudantes, sem mencionar a autoria. O processo de leitura de poemas é uma ação intencional que proporciona ao estudante o desenvolvimento de novas habilidades linguísticas, a leitura do poema vai além da primeira interpretação, desenvolve no estudante diversas concepções do que 
foi lido, ou seja, novas interpretações. É possível assim, através deste gênero, ler as entrelinhas, conforme reflexões de Colomer (2007, p.177):

Aprender a ler um poema é aprender a construir sua coerência, apoiando-se sucessivamente nas "zonas legíveis" para o leitor que busca o sentido através de entradas sucessivas. Com esta forma de proceder se ampliam as competências de análise e de integração como operações intelectuais básicas em nossa interpretação da realidade.

Ainda, a leitura de poemas desenvolve a interpretação no sentido de que "a semantização de todos os níveis do texto próprios da poesia requer um esforço interpretativo maior do que o habitual em outras leituras" (COLOMER, 2007, p. 177).

Inicialmente, a professora realiza a leitura dos poemas de forma expressiva, é uma forma de motivar os estudantes e demonstrar como as palavras criam vida através da entonação da voz e das expressões do rosto, Silva (2009, p. 110) enaltece que "A leitura expressiva não é dom, é aprendizado. Como tal, também pode ser ensinada. (...) Funciona, pois como estímulo, modelo desinibidor. Mostra como se lê com sentimento, com alma."

Após, ocorre a leitura coletiva e os estudantes selecionam em seus poemas preferidos e se surpreendem que em meio aos escolhidos havia poemas produzidos por seus colegas de escola. Este momento desperta nos discentes o interesse em participar do projeto apresentado, pois eles não reproduziriam poemas elaborados por terceiros, mas sim, suas próprias produções. Com os estudantes instigados, ficou mais fácil trabalhar a parte teórica, pois para produzirem seu poema precisariam conhecer as características deste gênero e saber aplicá-las em sua produção.

Esta etapa inicial serviu como motivação aos estudantes, de acordo com Cosson (2019), as atividades de motivação preparam o estudante para o gênero que será apresentado e mostram que o ensino da literatura não está desvinculado da Língua Portuguesa, mas sim que ambos estão inseridos um no outro.

O estudo do gênero textual ocorre inicialmente com a apresentação do ritmo, Sorrenti (2009, p.73), diz que "o ritmo é o elemento imprescindível num texto poético. O poema pode não ter rima, mas sempre terá um ritmo, um jogo de sonoro - que vai distingui-lo de um texto não poético". Para que haja a compreensão do ritmo, poemas como "Samba" de Almir Correia e "Trem de Ferro", de Manuel Bandeira são apresentados aos estudantes.

Em seguida, os estudantes aprendem sobre o uso das rimas, que são os sons coincidentes no final dos versos, no caso das rimas internas, ocorre no meio dos versos, para caso queiram usar em sua produção de texto, visto que não há uma obrigação quanto a isso. Neste sentido, os 
estudantes aprendem que, conforme Sorrenti (2019), a rima é um elemento secundário e pode ser dispensado, mas é um dos recursos disponíveis para o escritor, que pode dar mais harmonia ao poema. Os estudantes constroem rimas diversas com seus colegas sobre variados temas, para desenvolver esta habilidade.

Ainda, outro recurso apresentado é a disposição do texto, este elemento auxilia os estudantes a organizarem as palavras no texto, qual espaço utilizar e como aproveitá-lo com a finalidade de atingir seu objetivo que é dar sentido ao poema.

As figuras de linguagem são um recurso essencial na construção do poema, de acordo com Cegalla (1993), são três as figuras de linguagem: figuras de palavras; figuras de construção e figuras de pensamento. Neste âmbito são apresentadas aos estudantes as figuras de pensamento: metáfora, metonímia, perífrase e sinestesia; as figuras de construção: elipse, pleonasmo, polissíndeto, inversão, anacoluto, silepse, onomatopeia, repetição; as figuras de pensamento: antítese, eufemismo, gradação, ironia, personificação, reticência e retificação. Vale ressaltar que a docente considera a faixa etária dos estudantes para este estudo.

Ao explorar as figuras de linguagem, os estudantes percebem já conhecer muitas delas, não pelo nome, mas pelo uso, na construção do poema isso é o mais importante, conforme afirma Sorrenti (2009, p.84):

Tropeçamos nas figuras de linguagem a todo instante quando lidamos com bons textos poéticos, em prosa ou verso. O aluno não precisará, necessariamente, saber o seu nome para apreciá-los. Precisa apenas descobrir e/ou apreciar sua beleza, quando caminhar com elas pelos bosques da poesia.

Depois da leitura de obras poéticas e o estudo do gênero textual, chega o momento de produzir o texto, seguindo a sugestão de Cosson (2019), alternando as atividades de leitura e escrita para integrar teoria e prática. Ou seja, os estudantes além de produzirem seus poemas, são incentivados a lerem como está sendo desenvolvida sua construção, esses momentos são significativos, como ressalta o Estudante 27 “(...) acabamos desenvolvendo habilidades e temos experiências novas quando produzimos nossos poemas e quando ouvimos nossos colegas" (Diário reflexivo, estudante 27, 2019/II). Vale salientar que todas as turmas participaram desta produção, sendo ela individual e desenvolvida em sala de aula.

Para esta construção os estudantes têm a liberdade de escolher o tema, pois deste modo ficam mais envolvidos no trabalho, tem mais familiaridade com o texto e aguça ainda mais sua criatividade, buscando ressignificar os seus conhecimentos, de acordo com o seu tema, dentro da linguagem poética, assim “(...) permite liberdade de expressão, pois os alunos escrevem os poemas com tema de sua preferência (...). O recital de poesias não permite apenas demonstrar 
seu talento na hora de escrever um poema, mas sim recitar e dramatizar (Diário reflexivo, estudante 13, 2019/II). Neste sentido, a professora orientadora reflete sobre o papel social do projeto no que tange a coletividade, a equidade e a aprendizagem.

"O Recital de Poesia cria oportunidade para todos os alunos mostrarem seu potencial, seja na produção textual, na oratória ou em planejar apresentações criativas e autênticas. É um combo de oportunidade, conhecimento e aprendizagem." (Diário reflexivo, estudante 13, 2019/II).

Vigotski (1998, p. 115) expõe que “[...] o aprendizado humano pressupõe uma natureza social específica e um processo através do qual as crianças penetram na vida intelectual daquelas que as cercam". Nos processos de ensinar e nos processos de aprender, a mediação do professor e as relações sociais de produção do conhecimento científico são fundamentais para o desenvolvimento dos estudantes. Assim, para Vigotski (2004), o conhecimento do contexto social e cultural dos estudantes pelo docente é fundamental para que ocorra o desenvolvimento das funções psicológicas superiores, pois a aprendizagem dos indivíduos inicia muito antes da aprendizagem escolar; além disso, a aprendizagem escolar se baseia no estágio de desenvolvimento percorrido pelos estudantes, antes do ingresso na escola, seus conceitos espontâneos para a construção dos conceitos científicos. O processo de ensino cria uma Zona de Desenvolvimento para cada estudante, despertando os processos internos de desenvolvimento por meio das inter-relações com o outro.

Averbuk (1985, p. 68) afirma que "A poesia tem um papel no crescimento da personalidade, na medida em que, através do desenvolvimento da sensibilidade estética, de sua imaginação e criatividade, ela estabelece uma ponte entre o estudante e o mundo." De encontro com este pensamento, a produção do texto poema não tem tema pré-definido, visto que o projeto busca explorar a liberdade criativa do estudante, para que este possa expor através de suas palavras aquilo que lhe é mais próximo e íntimo, dessa forma vindo a criar laços entre o estudante escritor e seu texto, como demonstram o excerto do Estudante 4: "O recital é um projeto que ajuda os alunos a libertarem sua imaginação, a libertarem o seu talento que muitos jovens tem dentro de si e não tem coragem de mostrar para o mundo" (Diário reflexivo, estudante 4, 2019/II), em consonância o Estudante 58 afirma que: “(...) é uma maneira de fazerem os alunos aprenderem e usarem sua criatividade" (Diário reflexivo, estudante 58, 2019/II).

Ainda sobre a importância da liberdade criativa no processo de construção textual o Estudante 6 diz que: "É um recital livre (...), onde se pode escolher tema, fazer apresentações 
sobre o poema. Eu sinto que estou melhorando, nunca fui muito bom em escrever textos ou poemas, mas esse recital me ajudou (...)” (Diário reflexivo, estudante 16, 2019/II).

Seguindo este pensamento, em que é evidente o processo transformador pelo qual os estudantes passam ao participar de todo processo de construção de sua produção textual poética, Freire (1996), ressalta a importância da união entre professor e estudantes na busca por reconhecer as identidades e assumir os sentimentos, culminando em aceitação de si mesmo e dos outros, em relação a isso o autor afirma que:

\begin{abstract}
Uma das tarefas mais importantes da prática educativo-crítica é propiciar as condições em que os educandos em relação uns com os outros e todos com o professor ou a professora ensaiam a experiência profunda de assumir-se. (...) Assumir-se como sujeito porque capaz de reconhecer-se como objeto. A assunção de nós mesmos não significa a exclusão dos outros. É a "outredade" do "não eu", ou do tu, que me faz assumir a radicalidade de meu eu.
\end{abstract}

Em confirmação ao pensamento de Freire supracitado, os dizeres do Estudante 107 vão de encontro à relação entre o Projeto e a formação de um sujeito que reconhece sua identidade: “O recital é uma das maiores oportunidades que os estudantes tem de se expressar, demonstrar o que pensam e sentem, e até mesmo, o que eles têm de melhor" (Diário reflexivo, estudante $107,2019 / \mathrm{II})$.

O resultado de todo estas ações foi o esperado: inúmeros textos com diversos temas e uma singularidade incontestável em cada produção, em conformidade com a Figura 1.

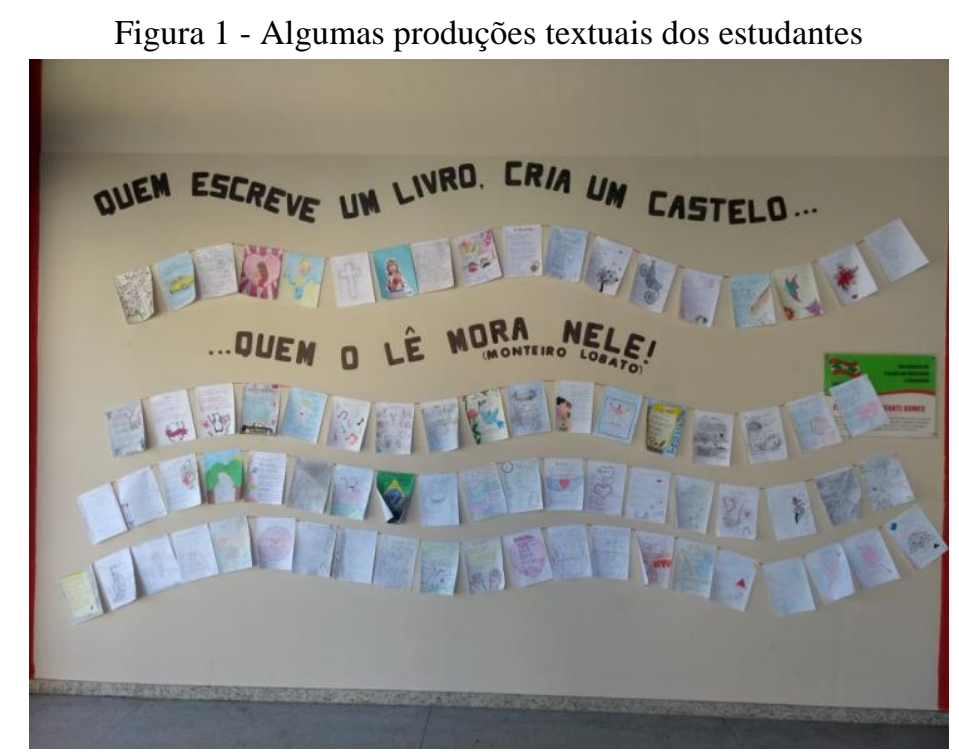

Fonte: Arquivo da escola, 2017.

Por meio de seus poemas, os estudantes expressam suas aprendizagens como ressalta o Estudante 8: "Com diferentes temas o recital explora a personalidade dos alunos e o que mais eles se identificam, relembrando fatos históricos, científicos e literários" (Diário reflexivo, 
estudante 8, 2019/II). O estudante 82 corrobora: "Foi algo de suma importância, para nós alunos, pois incentiva nossa criatividade e cognição e além de incentivar a escrita e despertar o interesse pela leitura. Dando direito de nos expressar através das poesias" (Diário reflexivo, estudante 82, 2019/II).

A liberdade contida no ato de escrever desperta o imaginário e suscita emoções, de acordo com Sorrenti (2009), as palavras que o estudante usa em sua produção revelam seu nível de linguagem, mas também sua capacidade de colocar em palavras suas ideias, o que vai de encontro a fala do Estudante 136: "Tenho liberdade em escrever o que estou sentindo, me sinto livre em poder expressar algo em um poema" (Diário reflexivo, estudante 136, 2019/II).

De acordo com a BNCC (2017), uma das competências que a Língua Portuguesa deve desenvolver é justamente tornar o texto um local propício para que o estudante possa manifestar o que sente e no que acredita (Figura 2). Freire (1996, p. 23), ressalta que a escola deve propiciar ao estudante "assumir-se como ser social e histórico, como ser pensante, comunicante, transformador, criador, realizador de sonhos, capaz de ter raiva porque é capaz de amar".

Figura 2 - Estudantes abordam temática social em sua dramatização

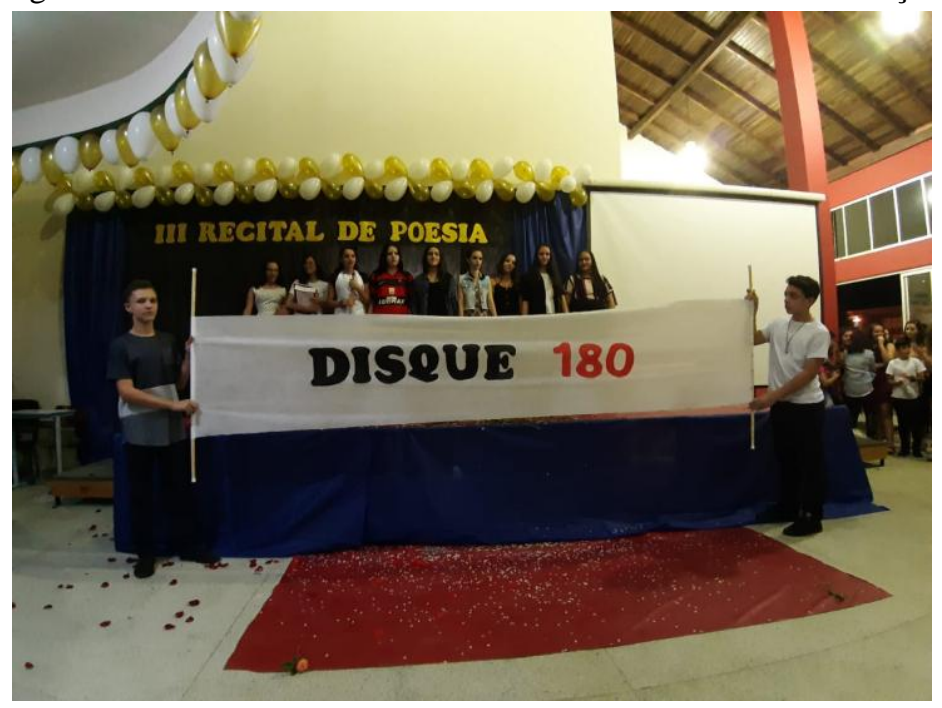

Fonte: Arquivo da escola, 2019

Afirmações como as dos autores supracitados, estão em consonância com o sentimento dos estudantes ao participarem deste projeto e de construírem seu saber poético:

\footnotetext{
"No recital é um momento que você pode expressar de uma forma que você pode estar passando e pode compartilhar para o público, é em sentimento de emoção, dor, amor, solidão, amizade tudo, é livre para fazer o que quiser. Nunca vi em nenhuma outra escola é uma nova experiência é muito legal saber coisas novas (...)" (Diário reflexivo, estudante 11, 2019/II).
}

Nesse sentido, Vigotski (2004) argumenta que a partir da reação do organismo a determinado estímulo, a emoção regula e orienta o organismo, bem como organiza internamente 
o comportamento. Para o autor a emoção está relacionada diretamente com a construção do conhecimento, e pode ser determinante na aprendizagem do mesmo:

Devemos considerar as emoções como um sistema de reações prévias, que comunicam ao organismo o futuro imediato do seu comportamento e organizam as formas desse comportamento. Daí abre-se para o pedagogo nas emoções um meio sumamente rico de educação dessas ou daquelas reações. Nenhuma forma de comportamento é tão forte quanto aquela ligada a uma emoção. Por isso, se quisermos suscitar no aluno as formas de comportamento de que necessitamos teremos sempre de nos preocupar com que essas reações deixem um vestígio emocional nesse aluno. Nenhuma pregação moral educa tanto quanto uma dor viva, um sentimento vivo, e neste sentido, o aparelho das emoções é uma espécie de instrumento especialmente adaptado e delicado através do qual é mais fácil influenciar o comportamento (VIGOTSKI, 2004, p. 143).

Para Vigotski (2004, p. 143) "as reações emocionais exercem a influência mais substancial sobre todas as formas do nosso comportamento e os momentos do processo educativo". Eidt e Tuleski (2010, p. 141) argumentam que "na medida em que não é possível separar os processos intelectuais e afetivos, é necessário estabelecer um vínculo que leve o aluno a dirigir a atenção ao objeto do conhecimento", como mostra a Figura 3.

Figura 3 - Afetividade expressa através da linguagem



Fonte: Arquivo da escola, 2019

Desse modo, o processo pedagógico de ensinar e de aprender motiva quando faz sentido para os estudantes, proporcionando uma melhor compreensão individual e coletiva, o que está expresso no excerto no Estudante 129: “Através de poesias, consigo mostrar meu verdadeiro eu, meu lado romântico e os romances fracassados na adolescência. É o evento que me enlouquece, que o coração acelera, que meus olhos transbordam de lágrimas" (Diário reflexivo, estudante 129, 2019/II). 
O próximo passo é a escolha dos poemas que mais se destacam em cada turma, aproximadamente cinco poemas. Um trabalho minucioso, detalhado e realizado por uma comissão de professores de diversas áreas do conhecimento e pela gestão da escola que examina cuidadosamente cada texto elaborado, observando os seguintes critérios: adequação linguística; marcas de autoria e convenções da escrita.

O critério de adequação linguística versa sobre o uso dos recursos poéticos, como os efeitos sonoros, a organização do texto, o uso de figuras de linguagem, e outros recursos que produzem efeitos estéticos como pontuação, posição das palavras e organização do espaço. $\mathrm{O}$ segundo critério trata das marcas de autoria, onde deve ser possível perceber através da leitura, os traços do autor no que ele quis expressar, sua autenticidade e primazia. O último critério, sobre as convenções escritas, aborda o emprego adequado da ortografia, acentuação, pontuação e o uso da oralidade em prol da poeticidade.

Depois de selecionados os textos, para cada poema é formada uma equipe, composta pelos estudantes da turma. O trabalho de cada grupo é construir a apresentação do texto em questão, já que este é selecionado para a culminância do projeto, o Recital de Poesia. Este processo inclui a dramatização dos poemas, intimamente ligado a expressão corporal e o uso da voz, o Estudante 31 reconhece a importância deste processo do projeto: “(...) O recital de poesias não permite apenas demonstrar seu talento na hora de escrever um poema, mas sim recitar e dramatizar" (Diário reflexivo, estudante 31, 2019/II).

Os estudantes trabalham em grupo e desenvolvem através dos ensaios, o uso do código verbal e não-verbal, aprendem como utilizar seu corpo através dos gestos, das expressões faciais e como usar sua voz através da tonalidade e do volume usado, essa leitura expressiva do poema traz aos estudantes a possibilidade de experimentar a arte cênica em suas apresentações. De acordo com Silva (2009, p. 133), “a produção artística coletiva favorece a criação de laços de interdependência entre os diversos participantes, num clima de respeito e de cooperação mútua", como mostra a Figura 4. 
Figura 4 - Cooperação no processo de dramatização

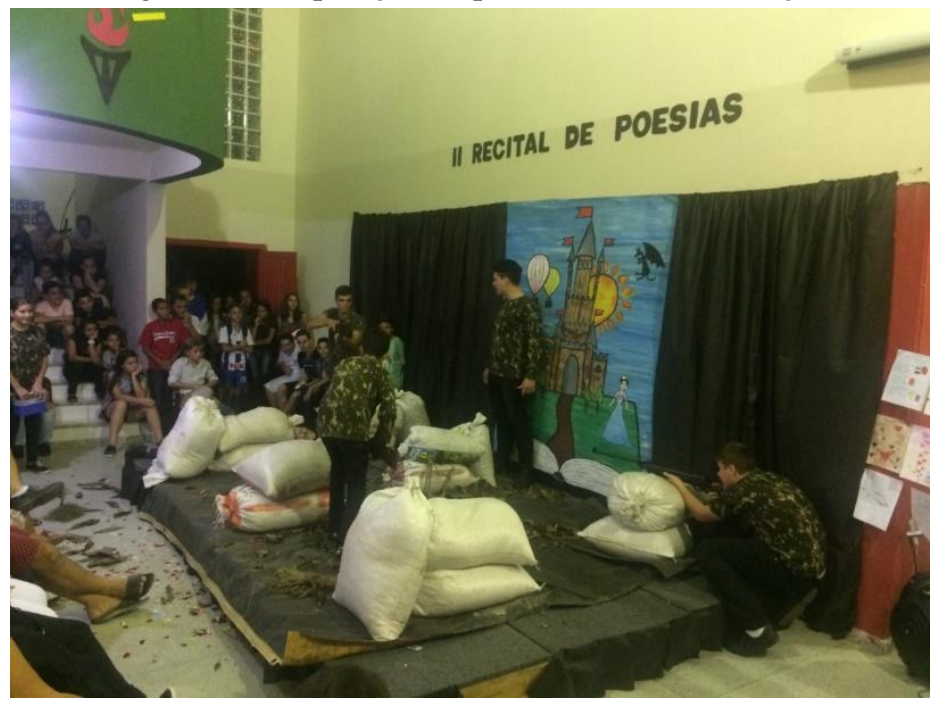

Fonte: Arquivo da escola, 2018

Neste processo artístico os estudantes sentem-se incluídos e valorizados independente da atividade que venham a desempenhar na dramatização, seja como protagonista, figurante ou na parte técnica, conforme os dizeres do Estudante 5: “(...) mesmo quem não recita o seu poema participa da mesma forma e assim ninguém fica de fora (...)" (Diário reflexivo, estudante 5, 2019). Em conformidade, o Estudante 94, reforça a ideia da unidade que se forma entre os estudantes no sentimento de cooperação e de valorização: “(...) seja quem declamou o poema ou quem jogou pétalas de flores, ninguém foi rebaixado independente do papel" (Diário reflexivo, estudante 94, 2019/II), conforme mostra a Figura 5 e 6 :

Figura 5 - Trabalho em equipe

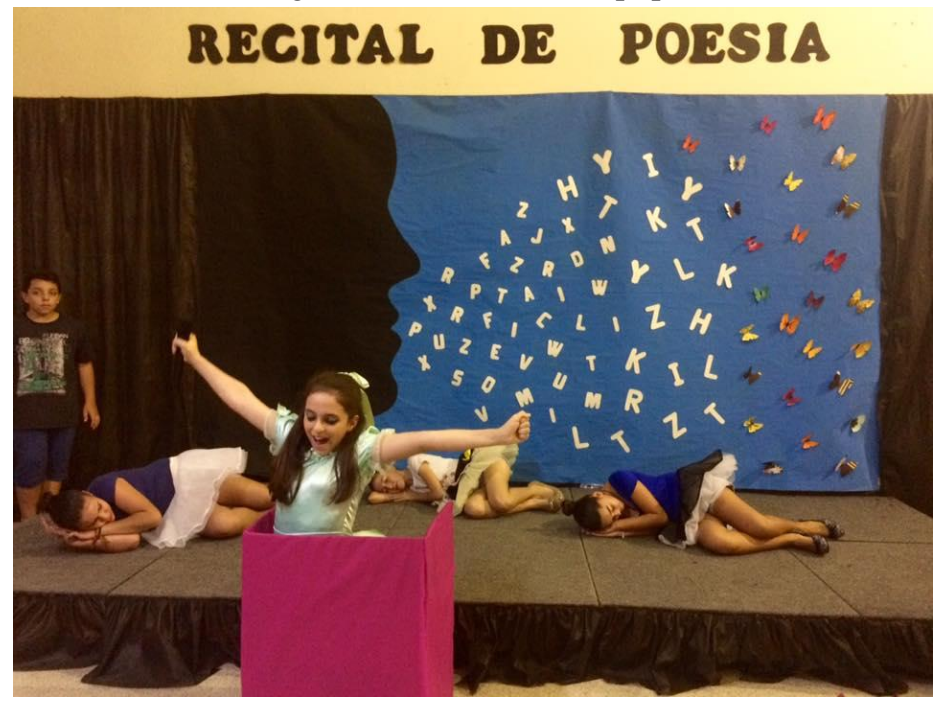

Fonte: Arquivo da escola, 2017. 




Fonte: Arquivo da escola, 2017.

Depois de muito trabalho criativo e ensaios, os poemas estão prontos para serem apresentados no Recital. Cada equipe é supervisionada durante todos os ensaios, tendo o suporte necessário para a realização do trabalho, pois a gestão escolar abraça o evento, essa mediação fica evidenciada com os dizeres do Estudante 36: "Nossa professora de português [...] deixa a poesia mais emocionante com teatro de alunos que não conseguem escrever um poema mas ela dá uma chance para essas pessoas se destacarem" (Diário reflexivo, estudante 36, 2019/II).

Essa mediação que o professor faz em todo o processo do projeto faz a diferença no que tange ao desenvolvimento do estudante, dando a este, subsídios para construir sua produção textual e expressar suas emoções, seja na escrita ou na dramatização. O professor que realiza a mediação, reconhece que o estudante tem algo para mostrar e é um sujeito digno de ser ouvido, assim promove que este manifeste sua leitura de mundo através de suas palavras:

No fundo, o educador que respeita a leitura de mundo do educando, reconhece a historicidade do saber, o caráter histórico da curiosidade, desta forma, recusando a arrogância cientificista, assume a humildade crítica, própria da posição verdadeiramente científica. A leitura de mundo revela, evidentemente, a inteligência do mundo que vem cultural e socialmente se constituindo. Revela também o trabalho individual de cada sujeito no próprio processo de assimilação da inteligência do mundo (FREIRE, 2013, p. 77).

O papel do professor em todo o Projeto, é algo que merece destaque, pois muitos estudantes evidenciam em suas falas o quão importante é esta mediação, conforme os excertos a seguir: "Eu sinto que estou melhorando, nunca fui muito bom em escrever textos ou poemas mas esse recital me ajudou, por que a professora ajuda e dá dicas ótimas" (Diário reflexivo, estudante 60, 2019/II), "a professora cobra muito de nós na elaboração dos poemas acho bem legal que ninguém fica de fora (...)" (Diário reflexivo, estudante 10, 2019/II), "Não gostava de 
falar em público, ficava com medo de rirem de mim, mas vi que não era um bicho de 7 cabeça era eu escutar a professora e deixar ir (...) (Diário reflexivo, estudante 20, 2019/II).

Com isso, o professor consegue extrair de seu estudante sua essência em sentimentos e emoções, “não se trata, portanto, de que a escola assuma a responsabilidade de 'fazer poetas', mas de desenvolver no aluno sua habilidade para sentir a poesia" (AVERBUCK, 1985, p. 67), como relata o Estudante 68:

\begin{abstract}
"Desde que entrei no $6^{\circ}$ ano tinha o recital de poesias um projeto feito pela professora de Língua Portuguesa, que nos proporciona demonstrar nossa angustia, sofrimento, alegria, é um modo de sermos nós, demonstrar nossos sentimentos em simples verso. A cada ano que passa, mais o evento cresce, emocionamos os olhares do público, em gestos, atuação ou em apenas palavras, não precisa ser a apresentação mais linda, mas simplesmente emocionar você e a todos" (Diário reflexivo, estudante 68, 2019/II).
\end{abstract}

Todo este percurso culmina na noite de socialização das produções, sendo então o evento Recital de Poesias envolvendo toda a comunidade escolar, onde a gestão, professores, estudantes e familiares se fazem presentes para prestigiar o trabalho desenvolvido (Figura 7).

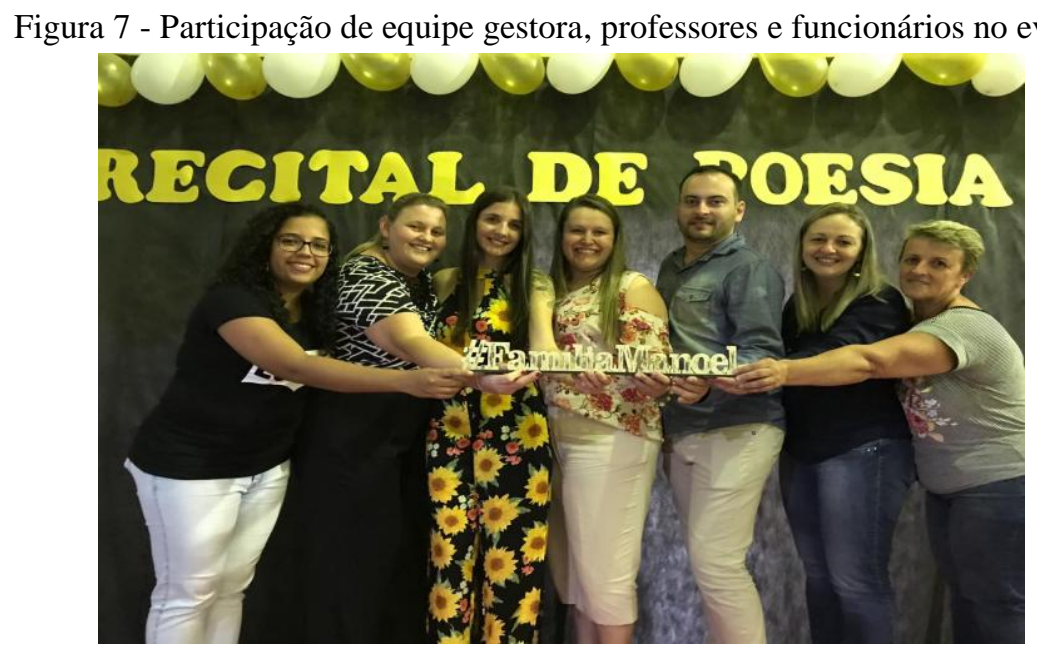

Fonte: Arquivo da escola, 2019.

É nítida a importância que há para os estudantes, de serem vistos como protagonistas pelos familiares neste dia, o que está evidenciado na fala do Estudante 114: “[...] bom de ver as famílias reunidas olhando as poesias dos seus filhos [...] (Diário reflexivo, estudante 114, 2019/II). Ainda neste sentido, o Estudante 47 diz que "resumindo em meias palavras, é um evento que juntou a família e a escola, que deu oportunidade de mostrar nosso talento, oportunidade de nos expressarmos... (Figura 8) que me deu oportunidade [...] (Diário reflexivo, estudante 47, 2019/II) 


\section{REGITAL DE POESIA}

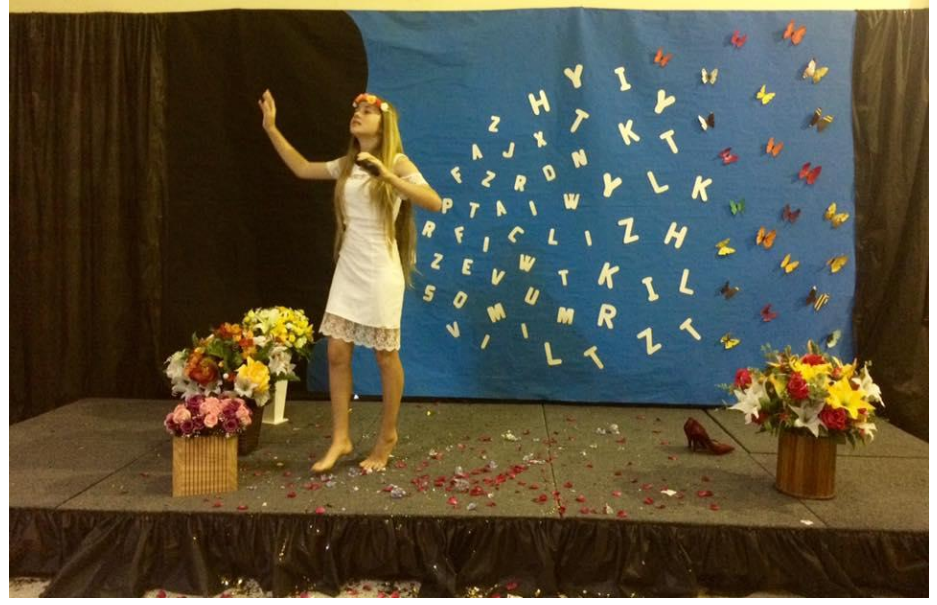

Fonte: Arquivo da escola, 2017.

Contribuindo com os excertos supracitados, Lombardi (2006), destaca a importância de a escola não ser uma instituição estática, mas que deve se transformar constantemente, acompanhando as diferentes formas de relação que as gerações produzem. Dentre estas, destaca-se a maneira de se conectar com a comunidade, incluindo as famílias dos estudantes.

Segundo Branden (1997), o ambiente familiar pode ter um impacto profundo no que se refere à autoimagem da criança, no senso de otimismo, nas relações sociais e, ainda ganhos da linguagem, na formação de conceitos habilidades motoras e de soluções de problemas. Sendo assim podemos inferir que as crianças cujas famílias estão envolvidas no contexto escolar são motivadas e conseguem ter um bom desempenho em relação às suas aprendizagens. Já os estudantes de pais ausentes, ou que raramente comparecem à escola, tendem a ter prejuízos em seu processo de construção de conhecimento.

Nesta vertente, através de seus poemas os estudantes se permitem novos sentimentos ou o aprimorar destes, como vemos no seguinte relato: "Melhora a vontade do aluno; melhora a autoestima e encoraja; está cada vez melhor" (Diário reflexivo, estudante 142, 2019/II), o estudante 29 afirma no mesmo sentido que o Projeto (...) mostra ao público da cidade os sentimentos dos estudantes, uns sobre os sentimentos, outros pela saudade, outros pelo esporte, enfim, vários temas muito legais (...) isso é muito legal e emocionante (...).” (Diário reflexivo, estudante 29, 2019/II)

O Projeto Recital de Poesia promove esta interação tão necessária entre escola e família, conforme a Figura 9, oportunizando aos familiares participarem de um momento mágico, verem os estudantes exercerem sua autonomia e demostrarem seus talentos, conforme relata o 
Estudante 42: "Um projeto pra demonstrar o talento dos alunos; uma noite que faz a todos se emocionar, pois as poesias contam a história de cada estudante, do que ele gosta, o que ele vive; faz os grupo se unir e a família participar” (Diário reflexivo, estudante 42, 2019/II).

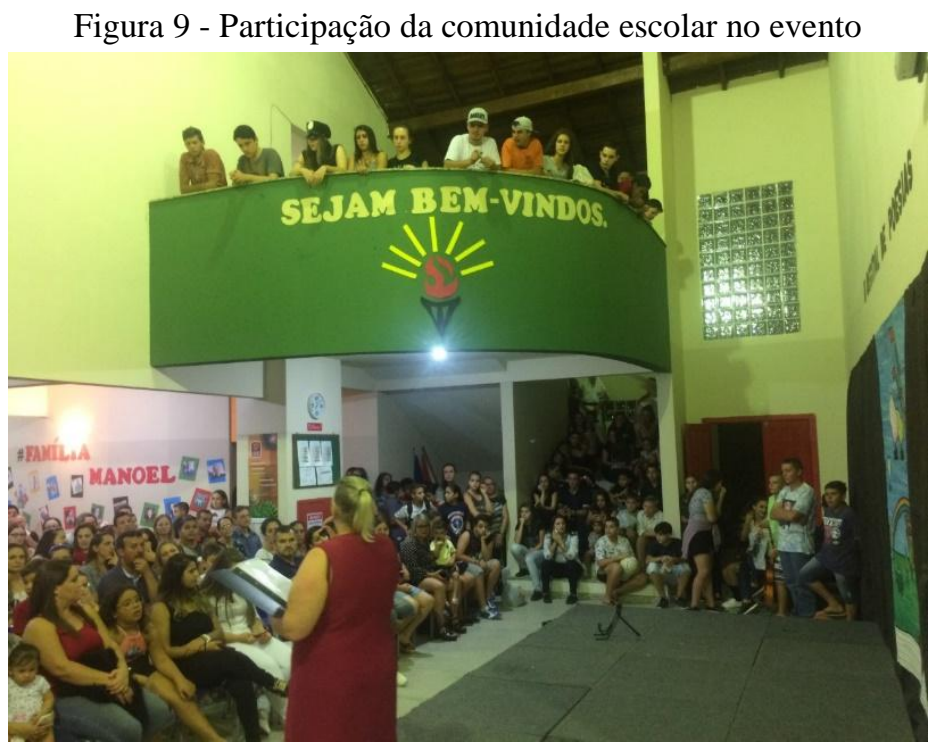

Fonte: Arquivo da escola, 2018.

Projetos como este são fonte de empatia e sentimento de pertença da comunidade escolar visto que os estudantes assumem a condição de protagonistas frente ao público e a sua produção textual de acordo com a escrita do estudante 3: “(...) poder me expressar na minha poesia foi muito divertido poder dramatizar e cada um de nós mostrar nosso talento, tirar a vergonha de nós amei cada momento" (Diário reflexivo, estudante 3, 2019/II).

Ao encontro destas falas, a professora orientadora relata que "é um projeto completo, pois desde o início até o fim são os estudantes os protagonistas do que é realizado, não é à toa que eles adoram participar" (Diário reflexivo, docente, 2019/II).

Finalizamos este artigo com os dizeres da professora orientadora que nos sensibiliza para a possibilidade de fazer a diferença na educação pública:

\footnotetext{
Além de tudo que foi citado, digo mais, este projeto aproxima nossos estudantes da sala de aula e reforça o vínculo que precisamos ter com eles. Desde a primeira edição do projeto até este ano foram descobertos e valorizados muitos talentos. Valorização é o combustível para manter estudantes ativos, criativos e que gostem de estudar. Estamos no caminho certo. (Diário reflexivo, docente, 2019/II).
}

Portanto, é possível levar a poesia com qualidade para a realidade de uma escola pública, mesmo com todas as mazelas pertinentes a este campo, pois o essencial se tem, que são os estudantes, faz-se necessário um professor motivado e com coragem de despertar a curiosidade pelo mundo encantado das letras, onde elas deixam de ser um amontoado de palavras e passam 
a dar sentido aos sentimentos e emoções do estudante, assim, fazendo deste um protagonista por meio da escrita.

\title{
5 ESCOLA E POESIA: UM CAMINHO SEM VOLTA
}

\author{
"Aqui me sinto em casa, \\ Me sinto protegido, \\ Gosto muito dos professores \\ E também dos meus amigos. \\ Talvez em outra escola eu devia estar no céu, \\ Mas pra que voar \\ Se aqui na terra existe a Família Manoel?" \\ (Estudante 52, Volta as aulas, 2018)
}

O lugar ocupado pela poesia na escola não pode ser resumido em um conteúdo em determinado momento do percurso formativo escolar. A poesia está entranhada na escola, pois a arte permeia o ambiente escolar, assim sendo deve ser trabalhada de acordo com toda amplitude de linguagem ao qual permite, o recital de poesia é um compilado de linguagem artística.

Um projeto significativo envolve desenvolver integralmente o estudante, onde este possa desenvolver suas habilidades, visando a promoção de sua autonomia e protagonismo. Todos os excertos apresentados evidenciam que a liberdade de expressão e integração com o público tem um significado real na vida dos estudantes, contribuindo para a construção de uma educação que inclua de forma democrática, respeitando e valorizando a individualidade de cada sujeito.

O sucesso deste projeto se deve a mediação de um professor comprometido não só em lecionar conceitos, mas em que os estudantes se apropriem destes e exerçam sua autoria de maneira a impactar sua vida e a dos que o cercam. Todos os processos de aprendizagem são importantes e assim sendo considerados pelo professor, alcançam êxito em seu ensino, da mesma forma o estudante reconhece o papel do docente, pois este deixa um pouco de si em cada produção discente.

Portanto, se de alguma forma este estudo nos diz algo, está latente que diz: há estudantes cheios do que dizer em nossas escolas, há professores de qualidade na rede púbica, há espaço para poesia independentemente da idade, há possibilidade de fazer a diferença com poucos recursos e há esperança através da arte.

\section{REFERÊNCIAS}

ANDRADE, Carlos Drummond de. A educação do ser poético. 103. ed. Rio de Janeiro: Jornal do Brasil, 1974. Disponível em: 
http://memoria.bn.br/docreader/DocReader.aspx?bib=030015_09\&pagfis=109989 Acesso em 05 mai. 2020.

AVERBUCK, Ligia Morrone. A poesia e a escola. In: ZILBERMAN, Regina (org.) Leitura em crise na escola: as alternativas do professor.4. ed. Porto Alegre: Mercado Aberto, 1985.

BRANDEN, Nathaniel. O poder da auto-estima. 7. ed. São Paulo: Saraiva, 1997.

BRASIL. Ministério da Educação. Secretaria de Educação Básica. Base Nacional Comum Curricular. Brasília, DF: MEC, 2017. Disponível em:

http://basenacionalcomum.mec.gov.br/images/BNCC_EI_EF_110518_versaofinal_site.pdf. Acesso em: 13 jan. 2020.

COSSON, Rildo. Letramento literário: teoria e prática. 2. ed. São Paulo: Contexto, 2019

COLOMER, Teresa. Andar entre livros: a leitura literária na escola. São Paulo: Global, 2007.

NOVAIS, Carlos Augusto. Elementos de composição poética: noções básicas. In: CUNHA, Leo (Org). Poesia para crianças: conceitos, tendências e práticas. Curitiba: Piá, 2012.

EIDT, Nadia Mara; TULESKI, Silvana Calvo. Transtorno de déficit de atenção/hiperatividade e psicologia Histórico-Cultural. Cadernos de Pesquisa, v. 40, n. 139, p. 121-146, 2010.

FIAMONCINI, Luciana. Dança na educação: a busca de elementos na arte e na estética. Pensar a Prática, v. 6, p. 59-72, 2006.

FREIRE, Paulo. Pedagogia da Autonomia - saberes necessários à prática educativa. São Paulo: Paz e Terra, 1996.

GODOY, Schmidt Arilda. Introdução à pesquisa qualitativa e suas possibilidades. Revista de Administração de Empresas. São Paulo, 1995.

LACERDA, Teresa; GONCALVES, Elsa. Educação estética, dança e desporto na escola. Rev. Port. Cien. Desp. [online]. 2009, v. 9, n.1, p.105-114.

LIBERALI, Fernanda Coelho. O diário como ferramenta para a reflexão crítica. Pontifícia Universidade Católica de São Paulo, 1999. Disponível em:

http://www.leffa.pro.br/tela4/Textos/Textos/Teses/fernanda_liberali.pdf Acesso em: 26 abr. 2020.

LOMBARDI, José Claudinei. A importância da abordagem histórica da gestão educacional. Revista HISTEDBR. Campinas, n. especial, p.11-19, ago., 2006.

MICCOLI, Laura Stella. Autonomia na aprendizagem de língua inglesa. In: PAIVA, V. L. M. O. (Org.). Práticas de ensino e aprendizagem de inglês com foco na autonomia. São Paulo: Pontes, 2007.

PINHEIRO, Hélder. Poesia na sala de aula. Coleção estratégias de ensino. Editora Parábola, São Paulo: 2018 
RIBEIRO, João Manoel. O valor pedagógico da poesia. Revista Portuguesa de Pedagogia, v. 41, n.2, p. 51-81, 2007.

SANTA CATARINA. Governo do Estado, Secretaria de Estado da Educação. Proposta Curricular de Santa Catarina: formação integral na educação básica. Florianópolis, 2014.

SILVA, Vera Maria Tietzmann. Leitura Literária \& outras leituras - impasses e alternativas no trabalho do professor. Belo Horizonte: RHJ, 2009.

SORRENTI, Neusa. A poesia vai à escola: reflexões, comentários e dicas de atividades. 2. ed. Belo Horizonte: Autêntica Editora, 2009.

VIGOTSKI, Lev Semyonovich. A formação social da mente: o desenvolvimento dos processos psicológicos superiores. 6. ed. São Paulo: Martins Fontes, 1998a. 191p.

VIGOTSKI, Lev Semyonovich. Psicologia Pedagógica. 2. Ed. São Paulo: Martins Fontes, 2004. 561p.

YUNES, Eliana; PONDÉ, Glória. Leitura e leituras da literatura infantil. São Paulo: FTD, 1988.

Recebido em: 8 de junho de 2020.

Aprovado em: 24 de agosto de 2020. 